1

\section{Different Aspects Connected with Lubricants}

3 Kirill Voinov*, Altyn Esbulatova, Yahia Ghellab, Oualid Belili, Tarek Nasr

$4 \quad$ Affiliation; forstar@mail.ru

5 *Correspondence author: forstar@mail.ru; Tel. +7-921-900-15-65

$6 \quad$ Affiliation esbulatova.altyn@mail.ru

7 Affiliation; ghellabyahia@yahoo.com

8 Affiliation; mohamedoualidbelili@gmail.com

9 Affiliation; tarek01021988@mail.ru

Saint-Petersburg National Research University of information Technologies, Mechanics and Optics, 197101, Kronverksky av. 49, Russian Federation

Abstract: In this paper we describe many important aspects connected with lubricants, namely: the most cheapest organic lubricant in the word, how effectively save lubricant between pairs of friction, what kind of rational shapes for the lubricant must be, what it will be connected with wear and tear using the new organic lubricant (for this purpose formulas and curves are shown in computer program MathCad with calculation). Moreover, there is one physical model which helps to catch car exhausted gases. In conclusion, some recommendations will be given to realize them into the practice during the operation for the different mechanisms including ecology.

Key words: lubrication; new organic lubricant; plastic; holding lubricant in mechanisms; clear ecology air; MathCad calculation; test bench; experiment; catch car gases

\section{Introduction}

It is common knowledge, that all lubricants have both positive and negative aspects. Firstly, we'll mark the first one:

- they decrease, as usually, the deterioration in pairs of friction (gear wheels, bearings, guides, cam mechanisms and so on);

- they essentially extinguish vibrations and oscillations;

- they decrease forces of friction and rotary moment;

- they reduce temperature in a zone of friction mobile contact;

- they partly help to smooth the surface roughness and protect it against the destruction.

All of them (aforesaid) play usually good role in various mechanical joints. But now (secondly) here they are the negative moments connected with lubricants which have some negative aspects:

$\checkmark$ liquid lubricant increases strain in the upper layers of surfaces for different parts in the mobile pairs of friction because of the deep penetration into each pits which every time there are in roughness. Reminding: from physics we know that liquid is an incompressible medium. By this reason, it passes the all load on the walls of pits and tries to broaden and to tear these pits. It's not good for the resistance to wear;

$\checkmark$ if we try to utilize natural oil (as, for example, from sunflower) then the whole complex procedures must be done beforehand, namely: plough, plant, cultivate, fertilize, pour, weed, gather the harvest, to work the harvest, to get oil at the works and so forth.

$\checkmark$ Moreover this product can not be saved too long in a good state in accordance with its qualities; 
$\checkmark$ the good properties of the natural oil can not be excellent for the long time because of ageing;

$\checkmark$ some useful components can be disappeared / evaporated unfortunately if the packing was opened or was not closed hermetically;

$\checkmark$ sometimes different lubricants smell badly and even harmful to persons (or annoying);

$\checkmark$ practically all lubricants are the dangerous and they can be on fire and excrete the perilous gases and evaporations for our life and for the environment too;

$\checkmark$ we have to guard such oil against the possible misappropriation in a special premises;

$\checkmark$ it is needed the special conditions into the shops where this oil must remain;

$\checkmark$ this definite kind of lubricant we usually can not mix with the other type of lubricant;

$\checkmark$ the empty packaging from under the definite oil must be cleaned carefully before the next process of packing filling will be for lubricant;

$\checkmark$ at last, all plastic lubricants vanish from the tight contact between two mobile surfaces very quickly because of press one body on the other one (for example, in gear wheels, in cams and so on).

As it will be shown below, many of enumerated negative aspects will be deleted at all by means of our novelties and recommendations. Moreover, both gases and lubricants can bring the definite harmful for our environmental [1-5, 10-16].

\section{Materials and Methods for the first suggestion}

Evidently, to diminish press from the liquid oil into the pit of roughness we must exchange the structure and shape of oil, for example: as elastic ball (hollow or complete), short and small macaroni, boublik or roller. Such forms don't permit this lubricant penetrate too deeply into the pit, not to bottom. Moreover, it is well known that to decrease the coefficient of friction we often use balls and/or rollers. In this case this effect will be obtained immediately. To prove this fact several experiments were made using physical macro-model as inverted pyramid on the one lateral side (on the outside) five transducers were fixed (Fig. 1).
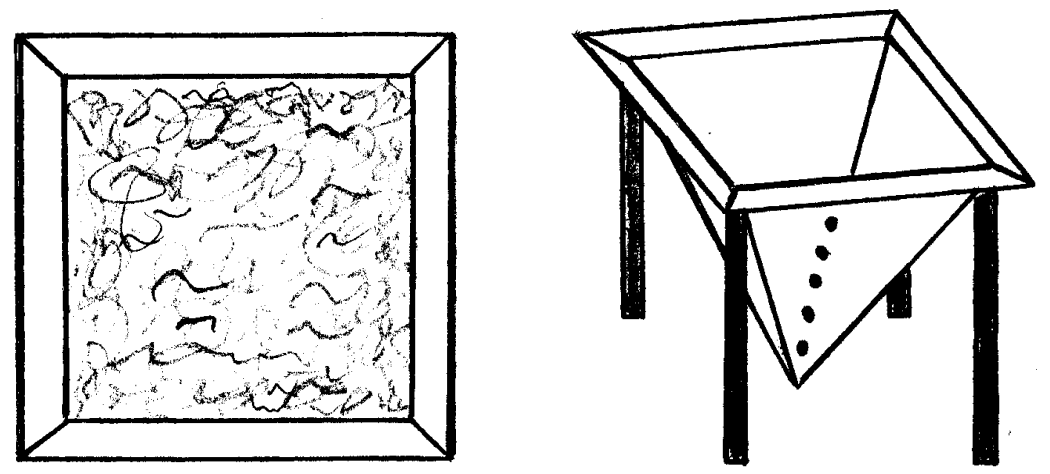

Figure 1. The physical macro-model with transducers to investigate the stress on the lateral side according to height: left view is the model with the definite media (water, oil, grease and so on including the new special suggested lubricant); right view is the pyramid with five transducers

Different lubricants (and even water) were put into this model in turn of course. Applying suggested new lubricant we managed to decrease the stress on the lateral side of pyramid from 
$30 \%$ to 10 times! It's the brilliant result. Such new shape of lubricant can essentially facilitate the work for the upper layers of all surfaces of friction during operation period. So, the first problem is solved in full.

\section{Materials and Methods for the second task connected with the previous one}

The question is - How can we quickly get such new shape of lubricant? Really, it's mighty easy. Let's use the electrical safety razor to cut hair from face (cheeks, chin and moustaches hair). In this case we get small elastic and fatty parts at once. Consequently, we've managed without many actions, namely: plough, plant, cultivate, fertilize, pour, weed, gather the harvest and so on to get good and the very cheapest organic lubricant. Besides, we save much money because we have just spent too small amount of electricity. But we can use even for this aim only small storage battery as well (without electricity at all)! Heir must be cut in dry way without any soap, foam/soapsuds or shampoo.

All species were placed into the small cupping-glasses (Fig. 2, left). Then several spacers were made (Fig. 2, right) with special grooves (Fig. 3, left) to catch species of hair energetically. It helps to save maximum species of hair in the zone of friction between of the two spacers. One of these spacers had the tail which we put into the spindle in the electrical hand-drill.
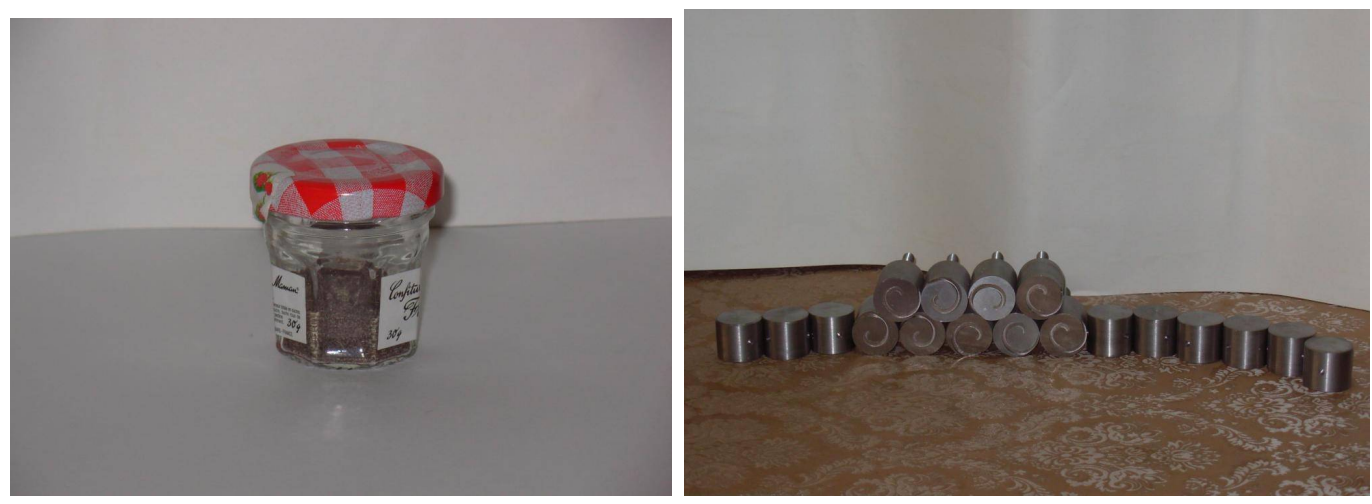

Figure 2. Cupping-glass (left) for hair and several spacers (right)
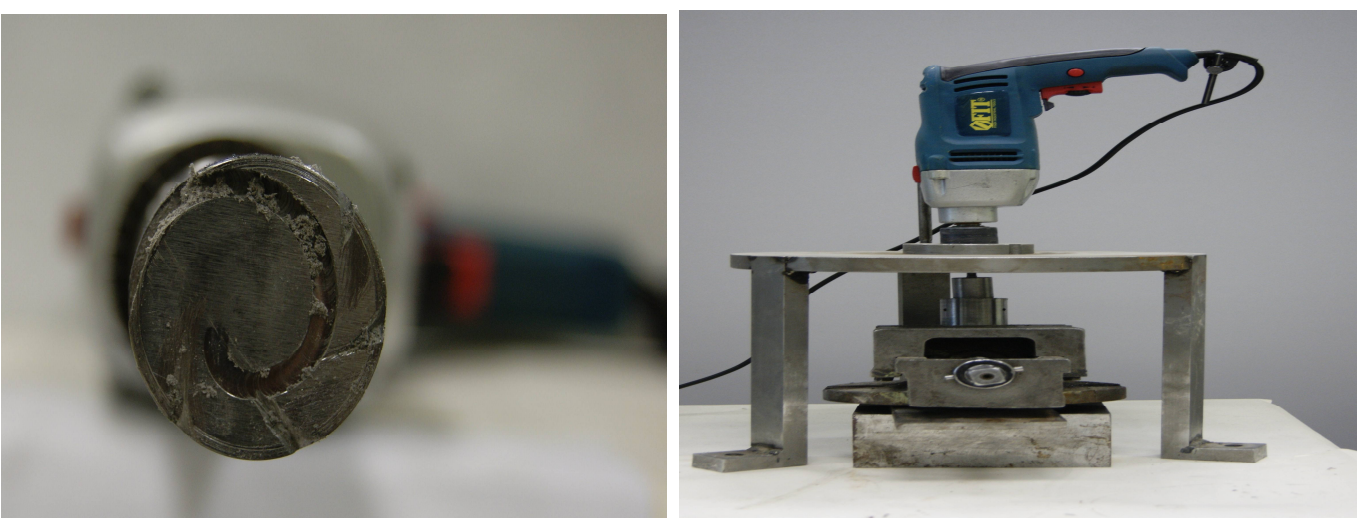

Figure 3. One spacer with grooves and hair lubricant in them (left) and installation to investigate the wear process for spacers using our new organic lubricant (right) 
100 To rotate upper specimen (spacer) we can use both boring machine and electrical hand-drill FINCH Industrial Tools FIT ${ }^{\mathrm{TM}}$ Serial NO: ID 0410298 having the speed of revolutions per minute from 0 to 1410 . At the same time the lower spacer must be fastened firmly in the vice.

During the tests connected with wear and tear some of metal specimens were covered with hair to determine the possibility of appearance for any corrosion. This experiment had the period in three months. Moreover, in this case corrosion was absent.

Furthermore, the investigation showed that this new lubricant hasn't harmful components.

The comparative curves of deterioration are given in Fig. 4 (without lubricant are upper curves - with theoretical approximation in computer program MathCad and with the statistical data) [6-9]. Beneath there are two curves of wear if the surfaces of friction were with the new organic lubricant.

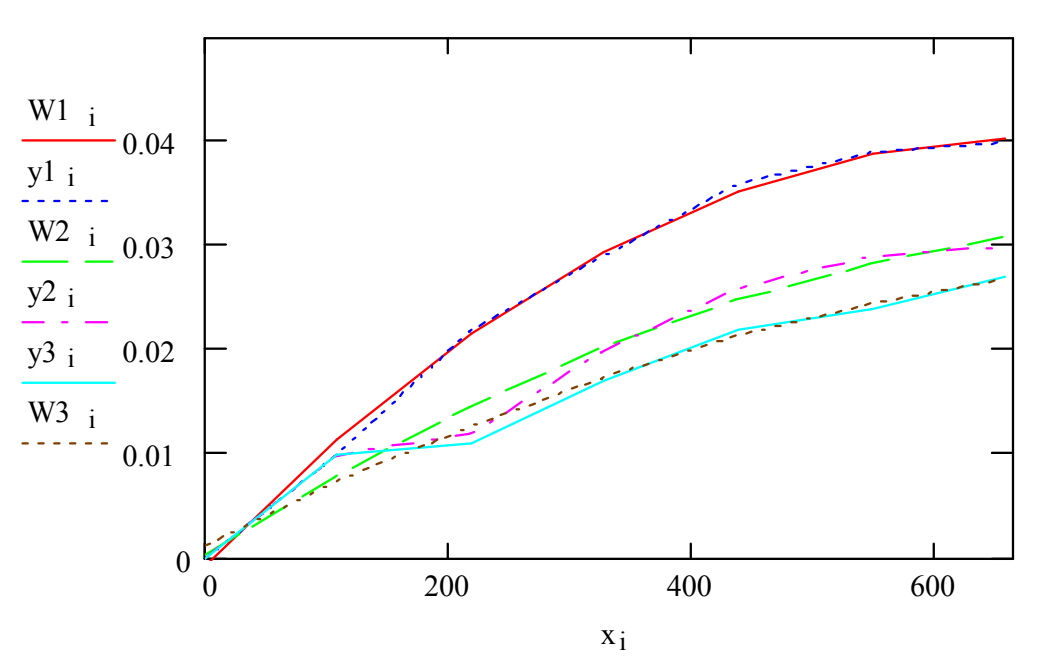

8

9

Figure 4. Results of deterioration for three steel specimens

The dimension on the horizontal axis is minute but for ordinate one is millimetre.

Theoretical equations which describe the wear $(\mathrm{W})$ in these experiments are the next:

$W 1=-1,071 \cdot 10^{-3} \cdot\left(x_{i}-x_{0}\right)^{2} / h^{2}+6,857 \cdot 10^{-3} \cdot\left(x_{i}-x_{0}\right) / h+0,029$

$W 2=-5,238 \cdot 10^{-4} \cdot\left(x_{i}-x_{0}\right)^{2} / h^{2}+5,071 \cdot 10^{-3} \cdot\left(x_{i}-x_{0}\right) / h+0,020$

$W 3=-3,81 \cdot 10^{-4} \cdot\left(x_{i}-x_{0}\right)^{2} / h^{2}+4,286 \cdot 10^{-3} \cdot\left(x_{i}-x_{0}\right) / h+0,017$

Designations and elucidations: Здесь $h=110 \mathrm{~min}$. (the step of observation the wear process); $x=660$ minutes (common time of trial); the number of points for measurements including the initial dot are seven $n=7$ where the deterioration is zero; $x_{0}$ - average meaning for the time of test. Broken lines in the chart $y_{i}$ correspond to the statistical data about deterioration but the smooth curves are the result of the theoretical approximation by parabola formula. Moreover, using well-known criteria written and suggested by professor V.I. Romanovsky we tried to find the unusual value in our statistical information.

Reckoning up the grand total connected with this investigation we can ascertain that hair can be effectively applied in practice to essentially decrease the wear in many pairs of friction. 
Note: as any organic material hair can not work if the temperature is too high. But, as we usually know, the negative temperature (approximately $-65^{\circ} \mathrm{C}$ ) is not obstacle for hair to use it.

\section{Materials and Methods for the third task connected with the plastic lubricant}

It is common knowledge that plastic lubricant very quickly disappear from the thick/dense contact in the mobile junctions for pairs of friction (in rack-wheel, in cams, in guides and so forth). In these cases our plastic lubricant disappears practically very quickly from the contact zone. We've managed to solve this negative problem by means of the simplest method. We applied the resilient rings which were tightly fastened to the definite places in mechanisms (Fig. 5). For example, They are installed on the both sides of the rack-wheel. The exterior diameter of our ring must be more than the outer diameter of the cogs peak (on $4 \mathrm{~mm}$ approximately). If the pair of the rack-wheels are mounted in a vertical position, the small capacity must be placed under the lower rack-wheel between of the two resilient rings. This capacity will save some amount plastic lubricant which can fall downwards during the revolution of rack-wheels. This lubricant will be used automatically because of contact between cogs and lubricant which is into the capacity in this case.

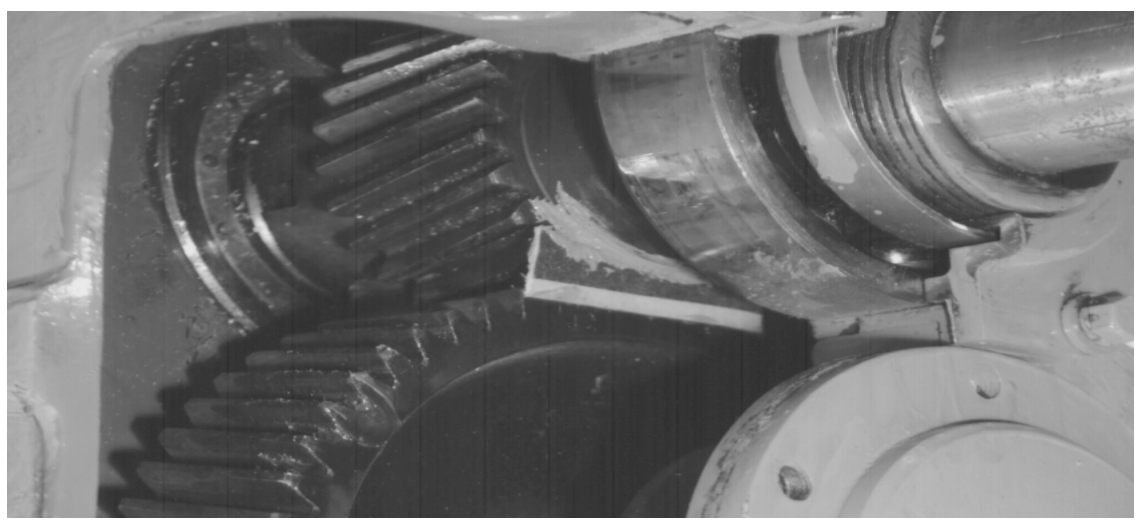

Figure 5. Fragment position if the part of the resilient ring was bonded to the rack-wheel

The analogous method was applied with the cam mechanism (Fig. 6).

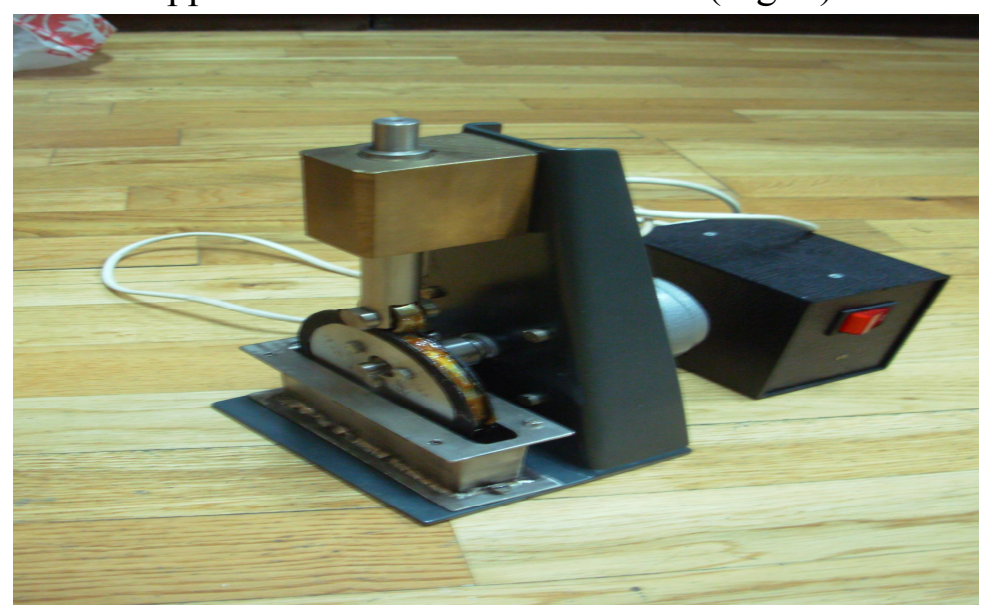

Figure 6. Design version how to save lubricant constantly between zone of contact cam-disc

Any deterioration in these described cases was essentially less than in a traditional design because of stable lubrication during the operation. 


\section{Materials and Methods for the fourth task connected with the evaporation and gases which are needed to catch}

Very many gases fly out from the different pipes of industrial works, boiler-houses and from the exhaust pipes in the cars and lorries. We applied the new method to catch these gases and bad evaporations. Gases by means of the pump were directed into the water reservoir where they lose their high temperature can not shoot up through the pipe into the fresh air. Some chemical elements will be dissolved into the water, others can settle on the bottom or float. But, unfortunately, some chemical components try to fly out from the water reservoir into the clean air. We've managed to liquidate this process at all. There are two main ways for it.

Firstly, above the water surface the light roof must be done. In this case, the condensed water with chemical elements and oil in the view as a drop or stream will fall into the warm water constantly. Physical model is given in Fig. 7.

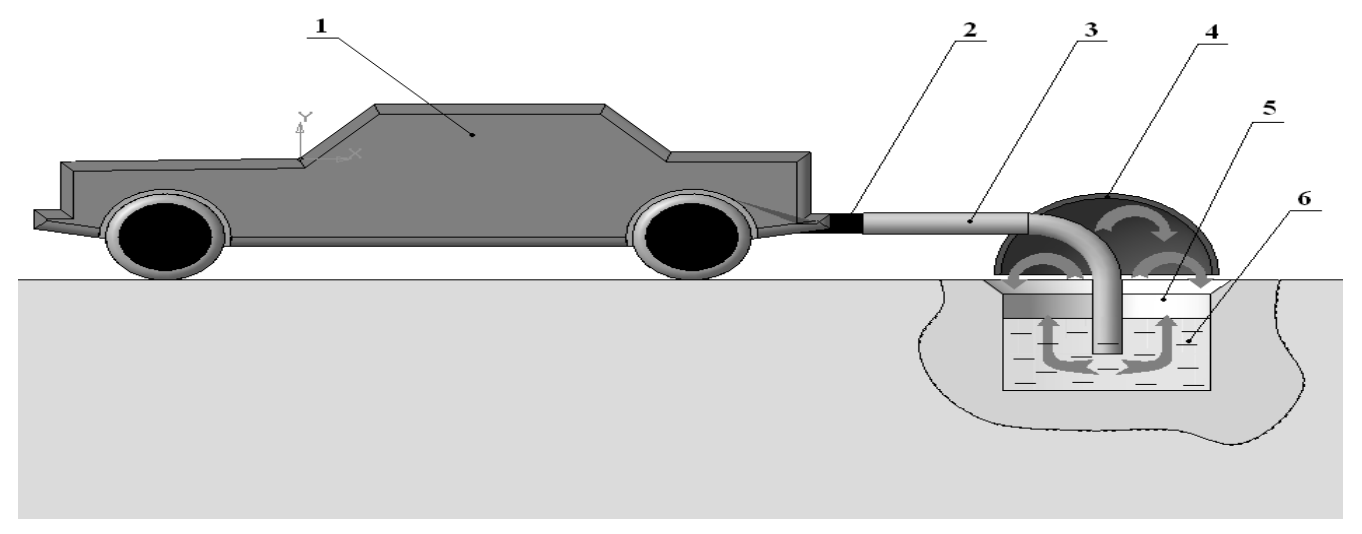

Figure 7. Grouping objects to investigate the effectiveness to reduce the harmful influence of the exhaust gases which fly out with oil from the car pipe: 1 - vehicle; 2 - coupling; 3 - hose/branch pipe; 4 - canopy/roof over the reservoir with water; 5 - oil or another film which covers the surface of water; 6 - water inside the reservoir

If it is needed to protect fresh air against harmful exhaust gases the water surface can be covered not only with oil film but, for example, but with coal, charcoal or wood sawdust. Taking into account that the gas chemical composition has the definite chemical components we can turn down into the water in good time another elements to get the full neutralization for gases.

In our experiment the water surface was covered with oil film which has different thickness $x_{i}$. The maximum thickness was $10 \mathrm{~mm}$. Intermediate meanings were the next: $0,2,4,6,8(\mathrm{~mm})$ with step $2 \mathrm{~mm}$. To determine the result personal computer was applied with mathematics casing MathCad [6, 9]. We tried to control how many gases bubbles will be on the oil surface which could went away in the clear air. To make the calculations we introduced the index variable $I$ for the all trails $n=6$ (Fig. 8). The approximation for statistical data was made using the parabola equation with parameters $a, b, c$ and constants were $\mathrm{H} 1$ and $\mathrm{H} 2$.

$$
\mathrm{i}:=1 . .6 \quad \mathrm{x}_{1}:=0 \quad \mathrm{x}_{\mathrm{n}}:=10 \quad \mathrm{n}:=6
$$


194

202

203

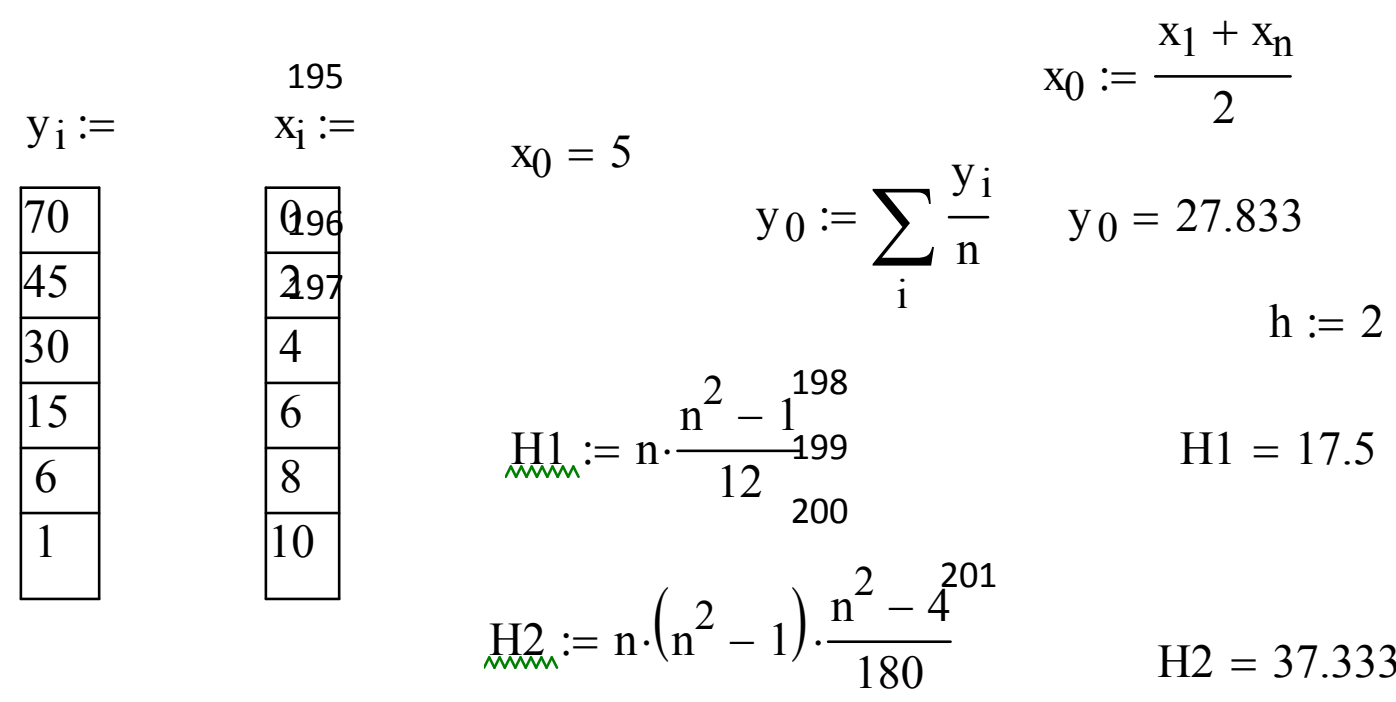

$$
\begin{aligned}
& \mathrm{a}:=\frac{1}{12 \cdot \mathrm{H} 2} \cdot\left[3 \cdot\left[\sum_{\mathrm{i}}\left[\mathrm{y}_{\mathrm{i}} \cdot(2 \cdot \mathrm{i}-\mathrm{n}-1)^{2}\right]\right]-\left(\mathrm{n}^{2}-1\right) \cdot\left(\sum_{\mathrm{i}} \mathrm{y}_{\mathrm{i}}\right)_{2065}^{204}\right. \\
& \mathrm{b}:=\frac{1}{2 \cdot \mathrm{H} 1} \cdot\left[\sum_{\mathrm{i}}\left[\mathrm{y}_{\mathrm{i}} \cdot(2 \cdot \mathrm{i}-\mathrm{n}-1) \underset{2}{2}\right]_{10}\right. \\
& \mathrm{a}=2.214 \\
& 208 \\
& \underset{w}{\mathrm{c}}:=\mathrm{y}_{0}-\frac{\mathrm{H} 1 \cdot \mathrm{a}}{\mathrm{n}} \\
& \mathrm{F}_{\mathrm{i}}:=\mathrm{a} \cdot \frac{\left(\mathrm{x}_{\mathrm{i}}-\mathrm{x}_{0}\right)^{2}}{\mathrm{~h}^{2}}+\mathrm{b} \cdot \frac{\mathrm{x}_{\mathrm{i}}-\mathrm{x}_{0}}{\mathrm{~h}}+\underset{212}{\mathrm{c}} \\
& b=-13.629 \\
& 211 \\
& \mathrm{c}=21.375
\end{aligned}
$$

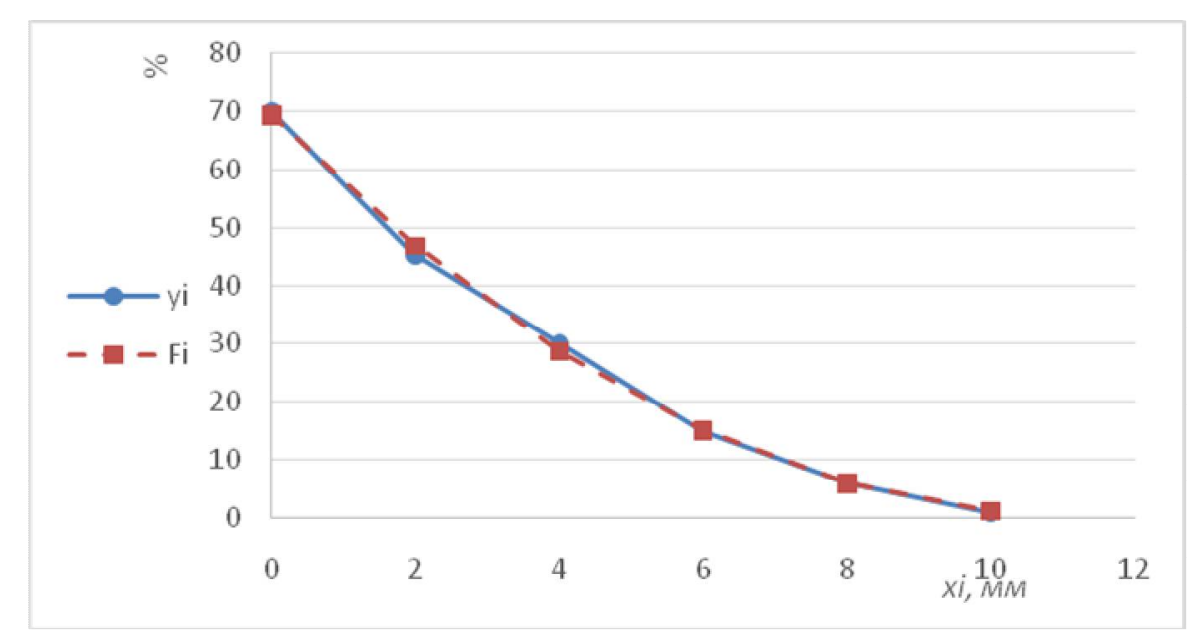

Figure 8 . Theoretical $\left(F_{i}\right)$ and real $\left(y_{i}\right)$ information in chart about how many bubbles $(\%)$ were on the oil film which had the different thickness $\left(x_{i}\right)$ 
221 The common conclusion connected with these experiment is the next: using additional cover of

222

223

\section{Materials and Methods for the fifth task connected with the problem how to catch any evaporations}

As we know, the evaporations can be quite different, namely: bad and harmful with the contrary smell (benzine, kerosene, spirit, oil, fuel, varnish and so on).

Unfortunately, some of them can disappear completely if their surfaces were not covered with hermetic lid. In this case we lose good products.

In Fig. 9 the effective construction is given to keep good products/liquids completely. For this aim there are two reservoirs which are connected by means of tube. In each reservoir there is hermetic film which doesn't permit for gases or evaporation fly out into the clean air. This film is disposed above the evaporation or gas. The smallest reservoir has the transparent walls. That's why because of film there is the possibility to see the level of gas or evaporation too in the big reservoir which has the dark walls $[1-5,16,17]$.

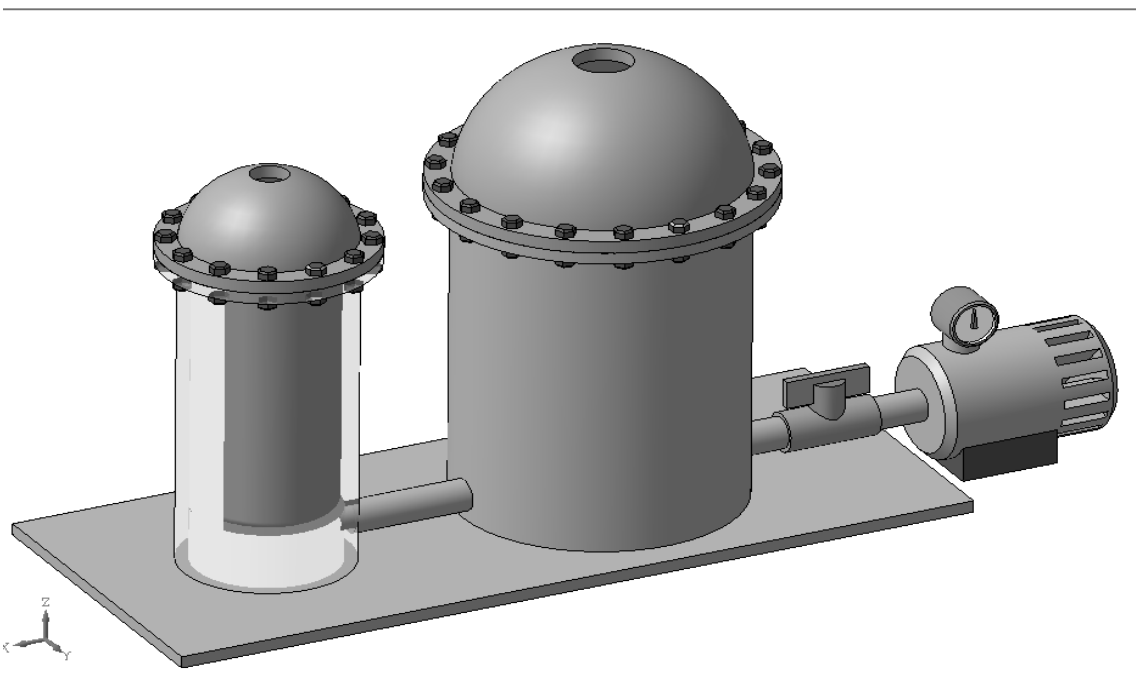

Figure 9. Working principles to catch hermetically different evaporations and gases

The motor can pump fuel/liquid or gases and it permits to pump out them. Experiments confirmed the effectiveness of our investigation and the new technical design. Gathered all evaporations or gases we can use or utilize in full.

\section{Results}

In this article many new peculiarities are demonstrated and depicted as the progressive ways, namely:

- to use new organic lubricant which showed the unique properties in pair of friction;

- how to save plastic lubricant in a mobile zone of the thick contact between of two parts in different mechanisms;

- how to protect fresh air against harmful exhaust gases from any car;

- how to catch good evaporations to use them once again in practice. 


\section{Short discussion}

During our work we attentively looked through many information (papers, patents, Internet, technical books and so on), linked with the items/problems which are given above. It seems to us, that our technical novelties have the definite indisputable advantages to be realized widely in practice. There are no publication made another authors in their investigations connected with plastic lubricants which have different shapes.

\section{Conclusion}

All important problem connected with lubricants, gases, evaporations, oils and fuels are solved. Consequently, these results must be used in practice in the wide plan. Many industrial works and organizations and test laboratories will get good profit. Moreover, it helps to save and improve our ecology.

\section{Acknowledgments}

In Saint-Petersburg our University ITMO politely left to us laboratory, devices and subsidiary apparatus to make many different investigations. We could work practically at any time during one year and a half. Thanks a lot for this possibility and help.

\section{Conflicts of Interest}

The authors declare no conflict of interest.

\section{References}

[1] Voinov, K.N. RU Patent №2604816: The way how to make the over-all cleaning for air basin against the production throwing from pipes. -2016 .

[2] Voinov, K.N. RU Patent №2656458: The trap for the harmful evaporations and smells. 2018.

[3] Voinov, K.N., Hildayati, A., Ghellab, Y. The reliability and over-all protection of the environment from the carcinogenic gases. Reliability, №2, 2018; pp. 46-49.

[4] Voinov, K.N., Nasr, T., Hildayati, A., Ghellab, Y. Non-linear versions to make the analysis of the statistical data. Transactions in Saint-Petersburg Electrical Engineering Sate University, №2, 2018; pp. 67-72. ISSN 2071-2359.

[5] Voinov, K.N., Ghellab, Y., Vasil'ev, V.A. Method of the technical diagnostic for the environmental in the conditions if it is being polluted with the car gases. Modern science: actual problems for theory and practice. Series: natural and technical sciences, №1, 2018; pp. 11-14. ISSN 2223-2966.

[6] Ivanovskiy, R.I. Computer technologies in science: practice of application for the system MathCad 7.0, MathCad 8.0 Pro and MathCad 2000 Pro: Educational aid. SPb., publishing house in SPbGTU, 2001; p. 200. ISBN 5-06-004434-3.

[7] Noskov, A.S. and Pay, Z.P. Technological ways to protect for the atmosphere against the harmful gases from the power engineering enterprises. Analytical review /RAN, University of catalysis named by Boreskov, K.G.; editor-in-chief Parmon, V.N. - Novosibirsk, 1996; p.156.

[8] Romanovskiy, B.I. Mathematical application for statistical data in the experienced work. M.L., OGIZ, Gostexizdat, 1947; p. 248. 
296 [9] Rumshiskiy, L.Z. Mathematical calculation for the results of experiment. M.: Science, 1971;

297 p. 192.

298 [10] Patent search which can be got by reference http://www.findpatent.ru/ patent/ $299211 / 2110318 . h t m l$. CFindPatent.ru, 2012-2017 [the date of circulation is 09.20.2018 ].

300 [11] Kalisinskas, D., Kerseys, A. Improvement of diesel engine ecological and economic 301 parameters by using hydrogen. Gliwice: Transport Problems, Volume 8, Issue 3; 2013; pp. 75 30283.

303 [12] Kumar, S.M. \& Ramesh, A. \& Nagalingam, B. Use of Hydrogen to Enhance the 304 Performance of a Vegetable Oil Fuelled Compression Ignition Engine. Int. J. Hydrogen Energy, 305 Volume 28, Issue 10; 2003; pp. 1143 - 1154.

306 [13] Merkisz, J., Pielecha, I., Pielecha, J., Szukalski, M. Exhaust Emission from Combat 307 Vehicle Engines During Start and Warm-Up. /Gliwice, Poland, Wydawnictwo Politechniki 308 Slaskiej: Transport Problems, Volume 6, Issue 2; 2011; pp. 121 - 126.

309 [14] Resitog `lu, I. A. \& Kecking, A. The pollutant emissions from diesel-engine vehicles and 310 exhaust after treatment systems. Tarsus Technology Faculty, Mersin University, 33500 Mersin, 311 Turkey, K. Altinisik, Department of Mechanical Engineering, Seljuk University, Konya, Turkey, 312 2003; pp. $14-21$.

313 [15] Singer, W., Schindler, W., Linke, M. Particulate and Smoke Measurement on Euro 4 314 Engines. Combustion Engines 1(124), 2006; pp. 54 - 59.

315 [16] Voinov, K.N., Hildayati, A., Ghellab, Y. New Effective Way to Protect our Air against 316 Gases from Plants, Boiler-Houses and Cars // Global Journal of Researches in Engineering, 317 Volume 17, No. 4, 2017; pp. 55-59. ISSN 0975-5861.

318 [17] Voinov, K.N. RU Patent №2679238: The way to catch the exhaust gases. - 2019. 